\title{
Maximising post-mining land use: Queensland Government reforms
}

\author{
S Cooper Queensland Government, Australia
}

\begin{abstract}
In 2016 in an atmosphere of increasing concern about potential risks of the resource industry, Queensland Treasury Corporation and the Queensland Government reviewed the State's financial assurance framework and mining rehabilitation outcomes. The Queensland Government responded to those reviews with a suite of significant reforms, designed to improve rates of progressive rehabilitation and minimise the State's risk in relation to the resource sector. In 2017, the government released the Mined Land Rehabilitation Policy, containing-for the first time-a clear statement of the expectations on mining companies in Queensland to progressively rehabilitate over the life of the mine and maximise post-mining land use. In 2018 legislation was passed, replacing the current financial assurance requirements with a Financial Provisioning Scheme, designed to minimise the financial burden on low-risk mines while providing full coverage for the State when required. The legislation also introduced requirements for companies with the biggest mines in the State to develop Progressive Rehabilitation and Closure (PRC) Plans. These PRC plans will communicate how resource companies will progressively rehabilitate mine sites and the criteria to which each area will meet in order to maximise post-mining land use. This paper will give an overview of the background and environment in which the reforms were designed, an overview of implementation so far and how the package of measures is supporting Queensland resource industry to increase the quality and quantity of progressive rehabilitation throughout the life of an operation to maximise beneficial post-mining land use.
\end{abstract}

Keywords: rehabilitation; reform; policy development; life-of-mine; mine planning; progressive rehabilitation; residual risk

\section{Introduction}

Mining is a valuable industry for Queensland's economy. Royalties earned from mining activities (including land rents) in Queensland totalled over \$4 billion in 2017-2018, predominantly from coal, with projections to increase steadily till 2022 (State of Queensland 2018a). In addition, the industry also provides opportunities for employment, regional economic development and essential commodities for use domestically, and international trade.

Mining in Queensland is considered a temporary activity and land use - companies are not required to buy the land they use for resource extraction and are given temporary access rights according to specified time frames. Of course, resource activities disturb land, to varying degrees, during their operations. However, assuming that rehabilitation is undertaken, mining will form only one of a number of sequential land uses over time.

The importance of sequential land use is recognised in the Multiple Land Use Framework endorsed by State, Territory and Australian government Ministers responsible for resources and energy portfolios (Standing Council on Energy and Resources 2013). Ensuring that rehabilitation of land impacted by mining activities to allow sequential land uses is also consistent with the intergenerational equity principle as set out in the Intergovernmental Agreement on the Environment, a schedule to the National Environmental Protection Council (Queensland) Act 1994 (Government of Queensland 1994b).

Because of the relatively temporary nature of resource extraction, an important role of the Queensland Government is to support the resources industry maximise the quality and quantity of land returned to a productive land use post-mining. 'Post-mining land use' has a specific definition under the Mineral and 
Energy Resources (Financial Provisioning) Act 2018 (Government of Queensland 2018) - however, in nontechnical language; it is the purpose for which the land will be used after rehabilitation has been carried out. For example, the post-mining land use could be a native ecosystem, grazing land, cropping land, or an industrial use.

The Queensland legislative framework recognises that without restoration or rehabilitation, mined land is unlikely to be suitable for sequential future use. The Environmental Protection Act 1994 (Government of Queensland 1994a) gives the authority for conditions about rehabilitation to be applied to environmental authorities. It also allows financial assurance or residual risk payments to be used in relation to the rehabilitation or restoration of land, managing the risk of achieving or maintaining rehabilitation.

Although the importance of enabling sequential land use has been identified, progressive and final rehabilitation and surrender of sites has been limited in Queensland. Rehabilitation can be seen as a burdensome activity that requires the investment of substantial resources often without a clear benefit to the company. Past practice has enabled some areas to be permanently alienated and are likely to be dependent upon long-term management to minimise environmental harm. For example, due to the nature of some structures and the materials they contain - such as waste rock dumps with acid producing material, tailings dams and final voids - they haven't generally been rehabilitated to be able to sustain a post-mining land use.

The performance of mining companies in rehabilitating land to support a post-mine land use can affect the opinion of communities in regard to mining companies. Lack of community confidence has the potential to affect the industry's social licence to operate and translate into objections to new mining proposals. Thus, the states' oversight in ensuring good rehabilitation and environmental outcomes is a key factor in whether the community will have confidence in the system of government to manage the mining sector.

The legislative frameworks supporting mining and the requirements and conditions placed on mining have evolved over time, moved between departments and steadily increased in clarity, effectiveness and rigour. The technology and skills available to achieve successful rehabilitation have also improved - the technologies available today enable extremely efficient mining operations. Sophisticated computer modelling and increasing automation allows companies to effectively plan and operate a mine from start to finish - including exploration, operations and rehabilitation activities - completely remotely in some cases. Mining companies have been operating in Australia and overseas now for over a century and many of the biggest have vast resources and skill sets to tap into when designing and operating mines. There is also a wealth of published literature about best practice mine rehabilitation, which is available to inform mine design and practice.

The importance to communities and individual landowners of the long-term impacts of resource extraction has become more prominent over time. While mining companies undertake resource extraction near towns and small communities across Queensland, they typically buy the land where the major disturbance will occur. However, the development of the gas industry in the Bowen and Surat basins significantly increased contact and required co-existence between large-scale resource projects with communities and farming operations. Landowners had to engage more heavily in understanding what the impact of resource activities would be to the form and productivity of their land and considering what would be necessary to return the land or manage the impacts. In order to support ongoing operations, industry has developed new technology to minimise its footprint of disturbance, for example the gas industry's use of hybrid drill rigs in development drilling activities as they are safer, more compact and drill faster with minimal disturbance, creating less impact to the environment and surrounding communities (Australia Pacific LNG [APLNG] ca. 2016).

In considering rehabilitation activity and success in Queensland, it has become apparent there are a number of settings or factors that influence the degree to which rehabilitation has been prioritised or achieved by industry and government. Building on Davis (2015), one could submit the setting and factors in Queensland include:

- The right regulations and regulators: legislative framework and requirements that ensure rehabilitation occurs - and the resources and capabilities of regulators to enforce these. 
- Community understanding and expectations: resource operations and/or failed rehabilitation affecting the community and the resultant increased media attention and community understanding of the risks of rehabilitation.

- Evidence for change: comprehensive analysis of the problem to support the need for change.

- Industry capability and maturity: equipment, programs, technology, as well as availability of skilled worker and of information on rehabilitation practices worldwide (lessons learnt).

- Clear expectations: clear policy on rehabilitation and closure of sites, and to what standards.

- Informed decision-making: an understanding of all regulatory obligations and possible costs to support decision-making considering the whole-of-mine-life.

The following sections first gives some background on the history and effectiveness of mining regulation in Queensland to achieve post-mining land use. The paper then goes into the environmental context of the recent reforms, discussing the views raised within the community and the outcomes of the reviews that ultimately shaped the development of the government's reform package. Key points are then outlined showing how rehabilitation requirements were enhanced within the current package of reforms, and considerations moving forward with regard to accountability and residual risk. The paper then summarises the key conclusions from the reforms and provides an analysis of how key factors contributed to the success of the reforms.

\section{$2 \quad$ Background}

\subsection{The evolution of the mining regulation framework}

Mining activity in Queensland is primarily managed by two pieces of legislation: Mineral Resources Act 1989 (MR Act) (Government of Queensland 1989) and Environmental Protection Act 1994 (EP Act) (Government of Queensland 1994a) both of which can influence rehabilitation outcomes. The genesis of the current regulatory framework spilt is a result of historical shifts in responsibility for the management of mining and environmental performance.

In 1994, the Criminal Justice Commission (CJC) released a report that revealed widespread non-compliance with environmental controls by mining operations and an expensive legacy for the State in rehabilitating mine sites. In response to the CJC report, the MR Act was amended to introduce tighter environmental controls including stricter requirements for miners to ensure rehabilitation of mine sites. It also required miners to prepare an environmental management overview strategy as part of their tenure applications (Department of Resources Industries 1992; Peel 2001).

However, the amendments to the MR Act did not resolve the internal departmental conflict between the traditional role of the former Department of Mines and Energy as the promoter and facilitator of mining in Queensland its other role as the environmental regulator of the industry (Peel 2001). Thus, in January 2001 the environmental management of mining was brought under the jurisdiction of the EP Act.

Currently, to conduct a mining activity, a company requires two permits:

- Tenure which authorises the activity and allows access to the land and resources (i.e. a tenure issued under the MR Act).

- A permit that details operating conditions that must be met in order to manage the environmental impacts and rehabilitation requirements on the authorised tenure (i.e. an environmental authority issued under the EP Act).

Both the MR Act and the EP Act are underpinned by environmental principles. Relevant objectives of the MR Act include minimising land use conflict, encouraging environmental responsibility and encouraging responsible land care management. The object of the EP Act is to protect Queensland's environment while allowing ecologically sustainable development. Both Acts, therefore, reinforce the idea that rehabilitation is 
primarily about ensuring that the disturbed land managed appropriately to ensure that the land can be used for a sequential post-mining land use and minimise the area of land sterilised. However, a lack of overarching government policy on the state's expectations for sequential land use meant that decision makers and industry did not have a consistent frame of reference when setting rehabilitation requirements for a mine.

\subsubsection{Increasing public concern: underestimated financial assurance and \$1 mine sales}

In 2014 a Queensland Auditor General's report into 'Environmental regulation of the resources and waste industries' was released (State of Queensland, Queensland Audit Office 2013). It stated the resources sector accounts for over two-thirds of all investment decisions in the state and noted the growth in employment in this sector from 16,500 to 73,400 positions over the past decade. The report stated this growth comes with 'increased risk of environmental harm and the possibility of adding to an estimated 15,000 abandoned mines and up to $\$ 1$ billion estimated cost if all mines were to be rehabilitated'.

The report found the bonds were 'insufficient to cover the costs of rehabilitation' and in the case of one particular mine the bonds held were only $1.5 \%$ of the estimated rehabilitation cost. The report also found the government department overseeing mine rehabilitation was reluctant to take action where the bonds may not meet the rehabilitation requirements. It also noted that in some cases, care and maintenance might be used as a means of avoiding rehabilitation.

In 2015-2016, there was a surge in public awareness and expectations around the role of government and industry in supporting the rehabilitation of mining activities in Queensland. Media coverage at the time indicated there was growing concern by the public about the adequacy of the State's provisions to account for the financial risk posed by a lack of rehabilitation. The Australia Institute polled thousands of people and published a briefing note presenting the results of community attitudes towards mine rehabilitation - including that less than $1 \%$ of people felt that it was acceptable for 'pits [to] remain and fill with saline or acidic groundwater, dirt and rock piles remain in a fenced off area' (The Australia Institute 2016).

Media articles began discussing the State's rehabilitation liability and the alleged loopholes in government rehabilitation requirements (e.g. Main \& Schwartz 2015). One phenomenon that received a large amount of media coverage and public scrutiny was the '\$1 mine sales' occurring in Queensland (e.g. Masige 2016; Willacy 2016). This involved instances of large international companies selling their assets to smaller operators with less overhead costs. While this arrangement did allow for further resource extraction at these mines, it also meant that considerable rehabilitation liability now rested with companies with less experience and financial resources. Two such cases were the sale of the Blair Athol mine near Clermont in central Queensland by Rio Tinto to the smaller operator TerraCom, and the acquisition of the Vale and Sumitomo owned Isaac Plains coal mine by Stanmore Coal. In both cases, the sale was made for $\$ 1$, with both new owners being given access to roughly $\$ 80$ million from the larger companies to meet their financial assurance obligations.

Related to this, concerns were also raised about 'share sales' that allowed the holder or operator of a mine to change without scrutiny by the government. As an example, Batchfire Resources Pty Ltd entered into a 'share sale agreement' with Anglo American Coal to receive ownership of the Callide mine in Queensland through the sale of shares. While the entity controlling the mine operation changed, the ABN (Australian Business Number) had not - which avoided the need for a new environmental authority or assessment by government of the suitability of the new controlling company (Robertson 2016).

In 2016, urgent amendments were passed to the EP Act to ensure that the (then) Department of Environment and Heritage Protection could effectively impose a 'chain of responsibility' so that companies and their related parties bear the cost of managing and rehabilitating sites. In the past 12 months, the Department of Environment and Heritage Protection had confronted increasing difficulties in ensuring that sites operated by companies in financial difficulty continue to comply with their environmental obligations. This included sites such as the Yabulu Nickel Refinery, Texas Silver Mine, Collingwood Tin Mine and Mount Chalmers Gold Mine. This emerged as a looming major problem with the downturn in the mining sector. Without additional 
powers in the EP Act, there was a risk that the State would incur operational and financial responsibility for sites in financial difficulty.

\section{Evidence for change: analysis and reviews}

The events in 2016 demonstrated that activities of the resource sector could lead to financial risk to the government and that there needed to be better identification and management of this risk for some sites, and for some companies. It became clear to government that a review of the effectiveness and ability of the financial assurance system to manage the risks to the State was necessary.

In response to concerns being raised about the financial assurance framework and progressive rehabilitation the Queensland Government undertook a number of reviews, data analysis and cross-government consideration in an attempt to understand the issue from a holistic perspective.

\subsection{Queensland Treasury Corporation review}

One of the key reviews was one undertaken by Queensland Treasury Corporation (QTC): Review of Queensland's Financial Assurance Framework (Queensland Treasury Corporation [QTC] 2017). QTC were commissioned to assist government in reviewing the State's financial assurance framework.

Government instructed that the desired outcomes that any reform would need to achieve were:

- Delivering a high level of environmental performance.

- Protecting the State's financial interest.

- Not a disincentive to industry.

- Satisfying community expectations.

The QTC review (2017) noted:

"Through its public statements, Industry has committed to delivering high standards of rehabilitation and to progressively rehabilitate sites over the life of the operation.

Currently, however, of the 220,000 hectares of disturbance, approximately 18,000 hectares (8 per cent) is classified by the Industry as progressively rehabilitated. Disturbed land that has been certified as rehabilitated totals 556 hectares, which is onequarter of a per cent of the total current disturbance.

The articulation of clear whole-of-Government expectations for rehabilitation and the collection of good quality data to evaluate performance are required to underpin a framework to improve the level of rehabilitation. This framework would enable early and ongoing planning and delivery of rehabilitation, provide greater certainty of progressive rehabilitation and certification requirements, address the issue of residual risk and support the development of a rehabilitation service industry."

The QTC review found in 2016 the State had an estimated rehabilitation cost of $\$ 8.7$ billion but held around $\$ 6.9$ billion in financial assurance. The discrepancy related primarily to the ability of companies to have their financial assurance 'discounted' by up to $30 \%$ through the financial assurance system at the time. These discounts were available for behaviours considered to lower a company's risk such as waste management, progressive rehabilitation and good financial standing.

The QTC review found that current resource sector financial assurance arrangements could be improved and that the gap between the area of land disturbed and rehabilitated has grown over recent years - concluding that without improved rehabilitation performance, the State will remain heavily reliant on the financial assurance system. The QTC review reflected some of the concerns raised in the media in 2014-2015, for example noting that where the sale of the resource asset occurs through the sale of shares in a company, the State cannot legally review or condition the change of ownership. As a result, stakeholders that have not 
undergone any assessment by the State of their suitability can conduct resources activities. The review also noted that sites in care and maintenance present a higher risk to the State.

The review stated there was a shared perspective amongst key stakeholder groups (including industry, environment and land groups, research bodies and the financial sector) that more frequent and proactive engagement and a clear, standardised approach by the State would allow for better facilitation of rehabilitation activities in Queensland (QTC 2017).

The QTC review recommended an alternative financial assurance system and a range of complementary measures to reduce the Queensland community's exposure to the financial and environmental costs of unrehabilitated land. The review noted that implementing these complementary measures would improve the outcome for the State through reduced exposure and proactive management of the remaining risk, irrespective of the financial assurance system adopted. The proposed measures aimed to deliver positive environmental outcomes, improve rates of site rehabilitation, and ultimately reduce the amount of rehabilitation required at the end of a resource site's lifecycle.

\subsection{Review of rehabilitation in Queensland}

In parallel and in support of the QTC review, the Department of Environment and Science (then Department of Environment and Heritage Protection) analysed available rehabilitation data to determine the scale and scope of the problem (State of Queensland 2017b).

The internal review found the gap between the area of land disturbed and rehabilitated had grown over recent years and was predicted to continue to expand. The data suggested that site-specific mining activities had disturbed approximately $0.1 \%$ of the mainland area of Queensland. Comparatively, agriculture is the most dominant land use in Queensland with $85.9 \%$ of the State currently used for cattle grazing. Despite mining's cumulative state-wide disturbance footprint being relatively small, the activity can be carried out in areas that provide favourable conditions for other activities such as agriculture, conservation, and urbanisation. When rehabilitation is not undertaken or fails, there is a greater risk of offsite impacts to land, water and the surrounding air quality, affecting individuals, communities and the environment. Where highrisk domains exist (e.g. hazardous waste rock dumps, tailings dams) the likelihood and consequence of the impact is often dependent on the standard of rehabilitation undertaken. Where large-scale disturbance and large earthworks have occurred and affected the geomorphology of land, impacts can occur to surface water flow, biodiversity corridors, and underground water systems.

The review also considered the rate of surrenders in Queensland. In terms of disturbed sites, surrender applications where significant disturbance has occurred were rare. For the few applications lodged for mineral activities (there have been none for coal mining), there was a lack of evidence relating to environmental performance, meaning applications were not progressed to surrender.

Reflecting the long history of mining in Queensland, there are more than 15,000 'abandoned sites' associated with historical mining activities. In a recent review, the government identified that of these; approximately 120 sites form the Abandoned Mine Priority sites with a combined area of disturbance of just over 10,300 ha. These sites have characteristics consistent with contemporary mines as they are typically defined today (e.g. an open cut pit or a large underground development created by modern, larger scale mechanised mining methods). The remaining $99 \%$ of the 15,000 'known' or 'identified' sites represent historical mining disturbances where there are generally very small workings associated with historical mining activities (State of Queensland 2018b). While the risk and level of disturbance of these sites varies, they all represent resource sites in Queensland that, for a variety of reasons, have not fully been rehabilitated or brought to closure before the responsible party left the site and, in most cases, have fallen to the government to manage.

\subsubsection{Review of best practice rehabilitation}

The Department of Environment and Science (then Department of Environment and Heritage Protection) also undertook an international jurisdiction analysis of best practice rehabilitation and rehabilitation policy 
(Bell 1996; State of Queensland 2017b). A summary of this analysis can be found in Appendix 3 of the 'Better Rehabilitation for Queensland' discussion paper (State of Queensland 2017c).

The review found that the expectations of rehabilitation of mined land differ across the world, however it is universally accepted that best practice mining is when mining companies:

- Take responsibility for carrying out their mining obligations.

- Plan for and achieve good rehabilitation outcomes.

- Make sufficient financial provisions to enable quality progressive and final rehabilitation to occur.

The review found that the framework for rehabilitation is largely similar across all Australian states and territories where rehabilitation conditions are typically included as part of the tenure authorisation or planning approvals. This concept allows strategic land use planning to be considered when conditioning rehabilitation. Queensland is the exception where rehabilitation conditions are set outside tenure or planning legislation and is instead considered under environmental legislation. Strategic consideration of sequential land use is, therefore, a challenge in Queensland.

Most jurisdictions require mining companies to undertake progressive rehabilitation. As well as minimising environmental risks and testing assumptions about the effectiveness of rehabilitation design, it is generally more efficient for an operator to carry out rehabilitation while operations are ongoing (e.g. cash flow is high, equipment and labour are readily available). Other Australian jurisdictions require some form of mine planning document to be provided to an administrator by the mine company. Queensland is unique in that while a mine planning document is required to be provided to the administering authority (a 'Plan of Operations', which outlines the activities to be undertaken over the next 1-5 years), it is not assessed or approved. While companies have to comply with their Plan of Operations, they can amend it at any time.

The review also found most of the jurisdictions benchmarked undertake consultation in developing mine planning documents, requiring that stakeholder expectations be detailed in the plan, which increases accountability to achieve agreements. The review also determined that peak bodies in Australia supported the concept of planning for and undertaking progressive rehabilitation as part of best practice mining methodology. The Minerals Council of Australia (2016) states that 'rehabilitation undertaken progressively during the mining process enables companies to meet rehabilitation obligations and minimise risk over the life of the operation'. The Minerals Council sees use of mineral resources as being one of many alternative land uses over time and says that the industry recognises its responsibility as a temporary custodian of land to contribute to sustainable land use outcomes.

Similarly, the Queensland Resources Council (QRC) acknowledges that resource developments have a limited lifespan, and are just one of many land uses over time. The importance of rehabilitation and returning the land to a sustainable post-mining land use is undisputed. QRC policy states that rehabilitation is a process that begins in the planning phase and resource companies should progressively rehabilitate land to minimise the disturbance footprint (QRC 2017).

\section{The Queensland Government's reform package}

It was clear from the reviews that there were a number of policy settings across government that need to be effective and cohesive in order to support industry to undertake progressive rehabilitation towards a clear closure outcome. Following the QTC review the Queensland Government adopted a Financial Assurance Reform Framework (State of Queensland 2017a). The package of reforms incorporates the following:

- Reforming the current resource sector financial assurance framework to establish the Financial Provisioning Scheme.

- Implementing the government's Mined Land Rehabilitation Policy.

- Expanding the range of surety providers available for the provision of financial assurance. 
- Improved management of sites in care and maintenance.

- Expansion of the abandoned mines program to improve management of legacy issues.

- Review of existing approval conditions on the sale of resource assets.

- Improved data analysis, information systems and governance framework.

- Residual risk policy development.

A project management office was established in Queensland Treasury with representatives from the Department of Environment and Science and the Department of Natural Resources, Mines and Energy charged with coordinating the reforms, facilitating consultation with stakeholders and driving delivery and implementation. These departments also resourced teams to develop and deliver new and enhanced policies, new legislation, and operational guidance. Each department took carriage over relevant reform initiatives and a timetable for development was drafted, based on the current status of policy consideration of each initiative.

Because of the complementary nature of their topics, Government released the first two discussion papers together in May 2017; one discussed the overarching Financial Assurance Framework Reforms (the FA Paper) and one proposed solutions to achieve 'Better Mine Rehabilitation for Queensland'.

The FA paper proposed a new Financial Provisioning Scheme (Scheme) that would allow for the assessment of resource sites individually based on their financial risk, and use a range of financial assurance arrangements that appropriately match the risk. In the Scheme, each resource site - or environmental authority (EA) - that meets certain criteria (for instance, its estimated rehabilitation cost is above a certain threshold) would be assessed and a Risk Category Allocation is made. This Risk Category Allocation would determine the form of financial assurance the EA holder must provide to the State. It was proposed the scheme manager, a statutory officer supported by Queensland Treasury, would administer the Scheme. The new scheme manager would be responsible for administering all holders' financial provisioning on behalf of the State of Queensland.

The Scheme was designed to improve the State's management of its financial risk in the event holders of a resource activity EA or small-scale mining tenure (holders) fail to comply with their environmental management and rehabilitation obligations. Over time, the Scheme would also be able to provide funds to support rehabilitation of abandoned mines and expand research into mine rehabilitation.

The Better Mine Rehabilitation for Queensland discussion paper set out the government's response to the QTC review's recommendation to 'develop clear government expectations for rehabilitation' and reflected the results of the review of best practice rehabilitation.

The discussion paper noted the widening gap between the amount of land disturbed by mining and the amount of land rehabilitated. It presented a proposed mine site rehabilitation policy that all mined land should be rehabilitated so that it is able to sustain a post-mining land use. The proposed policy for mine site rehabilitation in Queensland was detailed in a policy statement, the final version of which is provided below.

The proposed policy was the key component of an integrated mined land management framework. The proposed framework also included six delivery elements:

1. Introducing life-of-mine plans for site-specific mines.

2. Regular monitoring, assessment and reporting.

3. Enforceable requirements for progressive rehabilitation.

4. Clear completion and signoff requirements.

5. Performance-based incentives.

6. Good quality data for policy and regulatory implementation. 
The proposed integrated mined land management framework reflected that responsible environmental management over the life of a mining operation is essential for successful rehabilitation.

\subsection{Public consultation}

The government undertook broad and comprehensive consultation on both discussion papers, with departmental officers travelling across the State to Cairns, Emerald, Rockhampton, Townsville and Mackay as well as hosting meetings in Brisbane. Over the consultation period, hundreds of submissions were received and over 20 external stakeholder meetings held. Attendees at these meetings included industry, environmental groups, local and university representatives, and industry stakeholders including QRC, Australian Petroleum Production \& Exploration Association, Association of Mining and Exploration Companies.

Stakeholders generally supported the changes to the financial assurance system, with concerns about implementation, confidentiality, and how they would be 'risk' assessed. The proposed integrated mined land management framework consisting of the policy and the six delivery elements was also generally supported. Most stakeholders agreed that mined land should be progressively rehabilitated throughout the life of the mine and supported the introduction of the requirement for a site-specific mine to have a life-of-mine plan. The key concerns with the proposed policy largely centred on a desire for flexibility, a need for greater detail around implementation and the transitional arrangements and ensuring definitions are clear and unambiguous. Stakeholders continued to be consulted, including on the draft legislation, to ensure their concerns were considered where appropriate in finalising the policies and developing the legislation.

The outcomes of the consultation process were reflected in the form and design of the final Financial Provisioning Scheme and in the government's final Mined Land Rehabilitation Policy.

\section{$5 \quad$ Clear expectations: a new policy and legislative amendments}

The Queensland Government released its final Mined Land Rehabilitation Policy in September 2017 (State of Queensland 2017b). The policy clarifies the government's expectations for mining companies with regard to planning for and undertaking progressive rehabilitation over the life of the mine, and for minimising cumulative disturbance of land overall.

The Mined Land Rehabilitation Policy (State of Queensland 2017b) states:

"The Queensland Government is committed to ensuring land disturbed by mining activities is rehabilitated to a safe and stable landform that does not cause environmental harm and is able to sustain an approved post-mining land use. Land disturbed by mining activities will be rehabilitated progressively as it becomes available, to minimise the risks of environmental impacts and reduce cumulative areas of disturbed land. The progress and outcomes of progressive rehabilitation activities will be monitored and reported on to demonstrate how successful they have been in achieving progress towards the approved post-mining landform, and to inform corrective action where required. To provide certainty about the outcomes and timing of rehabilitation, all site-specific mines will prepare a Progressive Rehabilitation and Closure Plan (PRCP). The plan will include binding, time-based milestones for actions that achieve progressive rehabilitation and will ultimately support the transition to the mine site's future use.

Disturbed land associated with mining activities is considered available for rehabilitation unless it is:

- being actively mined;

- being used for operating mining infrastructure;

- overlaying a probable or proven resource reserve identified for extraction in the approved PRCP within 10 years; or 
- the site of built infrastructure that will be retained as a beneficial asset in the approved PRCP.

Land disturbed by mining activities is considered to be rehabilitated when it can be demonstrated it is safe, stable, does not cause environmental harm, and is able to sustain the post-mining land use approved in the PRCP."

\subsection{The right regulators: financial management moved to Treasury}

The Mineral and Energy Resources (Financial Provisioning) Act 2018 (the MERFP Act) (Government of Queensland 2018) also provided for the establishment of a Financial Provisioning Scheme (Scheme) to replace the current financial assurance arrangements for resource activities. The Scheme utilises a hybrid approach based on a pooled fund for EA holders deemed to be at low risk of default, and requiring sureties (such as a bank guarantee) for EA holders deemed to be a high risk of default or have large liabilities that would distort the viability of the pooled fund. The MERFP Act amends the financial assurance provisions of the EP Act. It retains the Department of Environment and Science's role in approving the estimation of the rehabilitation liability for a site but establishes a new 'scheme manager', to be located within the Treasury portfolio, which will be responsible for conducting financial risk assessments and allocating operators to either the pooled fund or a requirement for surety. This new financial assurance scheme relieves the burden of the costs associated with servicing a surety for low risk operators by allowing them to instead pay a cash contribution into a pooled fund. For higher risk operators, operations or where the scheme manager needs to ensure the integrity of the pooled fund, a full surety will still be required.

\subsection{The right regulations: enhancing rehabilitation requirements}

Implementation of the government's new rehabilitation policy was supported by legislative amendments. In November 2018, the MERFP Act was passed. The MERFP Act amended the EP Act to implement key elements of the Mined Land Rehabilitation Policy and introduce the new Progressive Rehabilitation and Closure Plan (PRC plan) requirements for large-scale mine sites.

The PRC plan requirement was integrated into the existing application and approval process for environmental authorities for new mines in order to minimise the regulatory burden on government and industry. All mining projects carried out on a mining lease that make a site-specific EA application will be required to provide a PRC plan. The PRCP plan will contain a Progressive Rehabilitation and Closure Plan schedule (PRCP schedule) which is a separate statutory approval document. Once approved, the PRCP schedule will be given to the applicant together with the EA. The PRCP schedule will contain milestones with completion dates for achieving progressive rehabilitation of the mine site.

This schedule of enforceable milestones and rehabilitation conditions are aimed at improving rehabilitation performance in the mining sector. The legislative amendments also include the introduction of mandatory PRC plan auditing and additional rehabilitation reporting requirements. The reforms will deliver benefits to industry by setting clear expectations on rehabilitation and signoff requirements and growing the rehabilitation services industry.

The MERFP Act also provided transitional arrangements for the application of the PRC plan requirement to existing mines. Transition will commence at a date set by the Environmental Protection Regulation 2008 (EP Regulation) (Government of Queensland 2008) which is likely to be in the latter half of 2019, allowing industry and government time to prepare for the new requirements.

Other benefits of the reforms include increased community confidence in the mining industry and the regulator, the delivery of high quality rehabilitation on the ground and a reduction in the rehabilitation liability for the state.

\section{Informed decision-making: residual risk}

Queensland Government policy states that resource companies must maximise the amount of land that is rehabilitated to a condition that can support a sequential land use, once resource activities have ceased. It is 
clear that rehabilitation must be undertaken progressively over the life of the mine and disturbed land rehabilitated in line with their PRCP or EA conditions prior to applying for the surrender of the EA.

However, even with the completion of rehabilitation to meet the PRC plans (for site-specific mine sites) or EA conditions (for all other resource sites) there will be some circumstances where ongoing monitoring and management of rehabilitation is needed and/or where there is the potential for rehabilitation to fail.

Residual risks are those risks remaining at a rehabilitated resource site once surrender of the EA occurs. Enhancing management of these risks is an integral part of achieving the outcomes of the Queensland Government's broader Financial Assurance Framework Reforms package.

The EP Act uses the term 'residual risk' for where there is the necessity to conduct ongoing activities or a risk that a rehabilitated area or structure may fail, requiring action to address or prevent potential environmental harm after surrender of an EA.

The government is committed to ensuring the residual risks of a rehabilitated resource site are appropriately identified and managed. The EP Act details existing residual risk requirements including environmental risk assessment, proposal of residual risk costs and potential to require a payment. Industry peak bodies and the broader community acknowledge the importance of having a payment as a pre-condition to surrender of an EA in order to allow the government to address residual risks. However, it was identified that the existing methodologies and processes linked to the requirement in the EP Act need further development. A lack of clarity about the residual risk requirements is considered by some to be a barrier to both transitioning sites to closure and investment in rehabilitation.

A key policy objective therefore was to provide for more certainty and transparency in the regulatory framework in relation to residual risk by clarifying methodology for environmental risk assessment and calculation of residual risks as well as providing certainty about when a payment will be required.

The Queensland Government released the 'Managing residual risks in Queensland' discussion paper in November 2018 for an 11 week consultation period. In order to meet the above policy objectives, this paper proposed:

- A new process to determine a cost estimate for residual risk, which will have two outputs:

o post-surrender land management requirements to minimise risk events, and

- a payment to cover risk events and post-surrender land management costs.

- New cost estimate methodologies including a simple calculation tool and expert panels.

- That informed by a cost estimate, the State will decide on a payment amount.

- Funds to be managed by the scheme manager under the MERFP Act.

- Post-surrender land management requirements to be recorded in a plan that is binding and enduring.

The residual risk project will help industry and government to get a much better understanding of the total cost of making certain decisions. By 'closing the loop' the residual risk project will allow a full cost benefit analysis of the potential costs of rehabilitation and any residual management to be considered at all stages of a resource activity's life.

Final residual risk proposals are being developed in response to consultation feedback (see Shrivathsa \& Cooper 2019). To enhance consideration of options and draw from other jurisdictions across Australia a multi-day workshop was created and hosted by Queensland. The workshop objectives were to share information about current residual risk related projects, identify common issues, opportunities and solutions and develop guiding principles to support consistent residual risk policy making across Australia. For a discussion of the process and outcomes of this workshop, please refer to 'An inter-jurisdictional approach to designing residual risk policy' (Shrivathsa \& Cooper 2019). 


\section{$7 \quad$ Discussion and conclusion}

There are a number of settings and factors that have and can influence the degree to which rehabilitation and mine closure has occurred in Queensland.

This paper highlights that in the process of development and delivery of holistic reforms the Queensland Government responded to or addressed each one of those settings. The comprehensive consideration of issues enabled government to design a reform package that reflected both the emerging community expectations and the requirements of industry.

These reforms truly are once in a lifetime. The involvement of QTC to undertake a comprehensive, independent review of the entire financial assurance framework was a critical step in increasing the understanding of the problem and the interconnectedness of the issues. Using a project management office staffed by multiple government agencies to oversee delivery of this huge suite of reforms has been integral to ensuring engagement by all relevant departments and timely delivery of the projects.

While the reforms are yet to be fully implemented, a number of important and historic milestones have been achieved. The release of a government Mined Land Rehabilitation Policy was a critical step in clearly stating the government's expectations. The passage of the MERFP Act implemented this policy and created a new, more tailored approach to financial assurance. The new PRC plan requirement will assist in improving the quality, quantity and outcomes of rehabilitation and increasing the transparency on the progressive and final rehabilitation plans of mining companies.

There are likely to be some teething issues with the implementation of these reforms, as with any large-scale reform involving a number of institutions. The potential benefits of the new framework - particularly the enhanced risk management through Treasury's Financial Provisioning Scheme (FPS) and the focus on quality progressive rehabilitation via the new PRC plan requirements - mean the initial efforts to transition sites are an entirely worthwhile endeavour for both industry and government, especially considering the lifecycle of many of these operations.

With the continued development of the residual risk work in progress, the State will have made huge leaps forward in clarifying the process and considerations around rehabilitation in the State of Queensland.

The Queensland Government's innovative reform package will, in time, improve rates of progressive rehabilitation and minimise the State's risk in relation to the resource sector. By supporting companies to achieve good rehabilitation outcomes and maximise the ability of disturbed land to be used for productive post-resource use, the State can enhance community confidence, support the continued social licence of the resources sector to operate in Queensland.

\section{Acknowledgement}

The author would like to acknowledge the teams who have been working incredibly hard on developing and delivering these reforms across Queensland Government. In particular, thanks to colleagues in the Environmental Policy team in the Department of Environment and Science - Geoff Robson, Lawrie Wade, Maria Rosier, Katherine Brown and Rebecca Barbierato as well as Kirsten Vagne, the head of the project management office for their dedication and determination. And thanks to Annie McCabe for her contributions and editing of this paper.

\section{References}

Australia Pacific LNG ca. 2016, Coal seam gas, viewed 25 March 2019, https://www.aplng.com.au/topics/coal-seam-gas.html Bell, LC 1996, 'Rehabilitation of disturbed land', in DR Mulligan (ed.), Environmental Management in the Australian Minerals and Energy Industries, University of New Sales Wales Press, Sydney, pp. 227-261.

Davis, C 2015, 'Environmental rehabilitation and mine closure', AusIMM Bulletin, February 2015 feature, viewed 25 March 2019 , https://www.ausimmbulletin.com/feature/environmental-rehabilitation-and-mine-closure/

Department of Resource Industries 1992, Environmental Management for Mining in Queensland: A Policy Booklet, Preparation Guide, Case Study, Queensland Government. 
Government of Queensland 2018, Mineral and Energy Resources (Financial Provisioning) Act 2018, Australia.

Government of Queensland 2008, Environmental Protection Regulation 2008, Australia.

Government of Queensland 1994a, Environmental Protection Act 1994, Australia.

Government of Queensland 1994b, National Environmental Protection Council (Queensland) Act 1994, Australia.

Government of Queensland 1989, Mineral Resources Act 1989, Australia.

Main, L \& Schwartz, D 2015, 'Industry insider warns taxpayers may foot bill for mine rehabilitation unless government, industry step up', $A B C$ News, https://www.abc.net.au/news/2015-09-19/taxpayers-may-foot-bill-for-mine-rehabilitation/6787954

Masige, S 2016, 'One dollar coal mine reopens, creates new jobs', Australian Mining, https://www.australianmining.com.au /news/one-dollar-coal-mine-reopens-creates-new-jobs/

Minerals Council of Australia 2016, Mine rehabilitation in the Australian minerals industry, an industry report commissioned by the Minerals Council of Australia, Sydney, viewed 31 July 2019, https://minerals.org.au/sites/default/ files/MCA\%20Publications/Mine\%2Orehabilitation\%20in\%20the\%20Australian\%20minerals\%20industry\%2025\%20Feb\%202 016.PDF

Peel, J 2001, 'An environmental revolution in the Queensland mining industry or just a changing of the guard? An analysis of the new regime for the environmental regulation of mining under the Environmental Protection Act (Qld)', Australian Mining and Petroleum Law Journal, vol. 20, no. 2, pp. 137-147.

Queensland Resources Council 2017, Rehabilitation and Relinquishment, viewed 13 January 2017, https://www.qrc.org.au/ policies/rehabilitation/

Queensland Treasury Corporation 2017, Review of Queensland's Financial Assurance Framework, https://s3.treasury.qld.gov.au/ files/review-of-queenslands-financial-assurance-framework.pdf

Robertson, J 2016, Start-up's purchase of Queensland coalmine avoids environmental scrutiny, https://www.theguardian.com/ environment/2016/feb/12/startups-purchase-of-queensland-coalmine-avoids-environmental-scrutiny

Shrivathsa, A \& Cooper, S 2019, 'An inter-jurisdictional approach to developing residual risk policy', in AB Fourie \& M Tibbett (eds), Proceedings of the 13th International Conference on Mine Closure, Australian Centre for Geomechanics, Perth, pp. 511-524.

Standing Council on Energy and Resources, 2013, Multiple Land Use Framework, COAG Energy Council.

State of Queensland 2017a, Financial assurance framework reform - Summary, viewed 28 March 2019, https://s3.treasury.qld.gov.au/files/Fin_Assurance_Framework_Reform_summary.pdf

State of Queensland 2017b, Mined Land Rehabilitation Policy, https://environment.des.qld.gov.au/management/pdf/mined-landrehabilitation-policy.pdf

State of Queensland 2017c, Better Rehabilitation for Queensland, Discussion Paper, viewed 25 March 2019 , https://s3.treasury.qld.gov.au/files/Better-Mine-Rehabilitation-in-Queensland-discussion-paper.pdf

State of Queensland 2018a, Budget Strategy and outlook: Budget Paper No. 2, viewed 23 March 2019, https://budget.qld.gov.au/files/BP2-2018-19.pdf

State of Queensland 2018b, Achieving improved rehabilitation for Queensland: addressing the state's abandoned mines legacy, Discussion paper, https://s3.treasury.qld.gov.au/files/8243_Abandoned-Mines-Discussion-Paper_v61.pdf

State of Queensland, Queensland Audit Office 2013, Environmental regulation of the resources and waste industries, https://www.parliament.qld.gov.au/documents/tableOffice/TabledPapers/2014/5414T4785.pdf

The Australia Institute 2016, Public opinion on mine site rehabilitation, Briefing note, Available:http://www.tai.org.au/sites/ default/files/Briefing\%20note\%20-\%20public\%20opinion\%20on\%20mine\%20rehabilitation\%20FINAL.pdf

Willacy, M 2016, 'Rio Tinto's \$1 sale of Blair Athol coal mine 'puts risk back on taxpayer', ABC News, https://www.abc.net.au/news/2016-07-12/rio-tinto-selling-massive-queensland-coal-mine-for-dollar/7588916 
